\title{
Circulating BAFF and CXCL10 levels predict response to pegylated interferon in patients with $\mathrm{HBeAg}$-positive chronic hepatitis B
}

\author{
Apichaya Khlaiphuengsin, ${ }^{1}$ Natthaya Chuaypen, ${ }^{1}$ Nattiya Hirankarn, ${ }^{2}$ Anchalee Avihingsanon, ${ }^{3}$ \\ Megan Crane, ${ }^{4}$ Sharon R. Lewin, ${ }^{4}$ Pisit Tangkijvanich ${ }^{1}$
}

\begin{abstract}
Background: B-cell activating factor (BAFF), an essential cytokine for B lymphocytes activation, has been implicated in the pathogenesis of chronic viral hepatitis. However, the role of BAFF in patients with chronic hepatitis B (CHB) undergoing antiviral therapy is unknown.

Methods: Patients with HBeAg-positive CHB treated with 48-week pegylated interferon (PEG-IFN; n = 42), who had stored plasma samples during treatment were recruited. Serial plasma levels of BAFF and C-X-C motif chemokine 10 (CXCL10) during therapy were measured.

Results: Combined response (CR), defined as HBeAg seroconversion with HBV DNA $<2,000 \mathrm{IU} / \mathrm{mL}$ plus $\mathrm{HBs}$ Ag decline $\geq 1 \log _{10} \mathrm{IU} / \mathrm{mL}$ at 24 weeks post-treatment, was achieved in 11 (26.2\%) patients. BAFF levels were elevated during treatment but decreased to pre-treatment levels after PEG-IFN cessation in both responders and non-responders. Low baseline BAFF $(<770 \mathrm{pg} / \mathrm{ml})$ and high CXCL10 $(\geq 320 \mathrm{pg} / \mathrm{ml})$ levels were independently associated with CR in multivariate analysis. Baseline CXCL10/BAFF ratio of $\geq 0.45$ was predictive of CR with positive and negative predictive values of 61.5 and $89.7 \%$, respectively.
\end{abstract}

Conclusions: In summary, low baseline BAFF and high CXCL10 levels were associated with treatment response to PEG-IFN. The combined measurement of these immune markers may help individualized decision-making in patients with $\mathrm{HBeAg}$-positive CHB.

Key words: BAFF, B cells, APRIL, CXCL10, IP-10, Peginterferon, hepatitis B, HBsAg

\footnotetext{
From:

${ }^{1}$ Center of Excellence in Hepatitis and Liver Cancer, Department of Biochemistry, Faculty of Medicine, Chulalongkorn University, Thailand

2 Center of Excellence in Immunology and Immune-mediated Diseases, Department of Microbiology, Faculty of Medicine, Chulalongkorn University, Thailand

HIV Netherlands Australia Thailand Research Collaboration (HIV-NAT), Bangkok, Thailand

4 The Royal Melbourne Hospital at the Peter Doherty Institute for Infection and Immunity, The University of Melbourne, Melbourne, Australia
}

\section{Corresponding author:}

Pisit Tangkijvanich

Center of Excellence in Hepatitis and Liver Cancer,

Department of Biochemistry, Faculty of Medicine,

Chulalongkorn University,

Rama IV road, Bangkok, 10330, Thailand

E-mail: pisittkvn@yahoo.com

\section{Introduction}

Chronic hepatitis $\mathrm{B}$ virus (HBV) infection is associated with diverse clinical manifestations including chronic hepatitis, cirrhosis and hepatocellular carcinoma (HCC). ${ }^{1}$ Current therapeutic options for chronic hepatitis $\mathrm{B}(\mathrm{CHB})$ include oral nucleoside/nucleotide analogues (NA) and pegylated (PEG) in terferon (IFN). Compared to NA, PEG-IFN offers a finite duration of therapy and is associated with higher rates of sustained off-treatment response and hepatitis B surface antigen (HBsAg) clearance. ${ }^{2}$ However, the use of PEG-IFN is hampered by potential adverse events. Therefore, a biomarker that could predict a high likelihood of PEG-IFN responsiveness would be highly desirable.

Current evidence has indicated that the outcome of HBV infection is determined by immune-mediated host-virus interactions. ${ }^{3}$ Indeed, effective control of $\mathrm{HBV}$ infection involves the coordinated actions of both innate and adaptive immune responses. At early onset of acute infection, vigorous 
and specific B and T-cell responses participate in the process of viral clearance and self-limited liver injury. Conversely, the immune activity is functionally-impaired in individuals evolving to chronic HBV infection. It is well recognized that HBV-specific T cells play a major role in the efficacy of the adaptive immune response and ultimately determine clinical outcome of $\mathrm{HBV}$ infection. ${ }^{4}$ In contrast to accumulating data of T-cell immunity, less is known about the role of B-cell-mediated immune response in the pathogenesis and treatment outcome of $\mathrm{CHB}$.

B cells play an important role in humoral immunity by producing antibodies, inducing immunomodulatory cytokines and influencing the T-cell response. ${ }^{5}$ Differentiation and proliferation of $\mathrm{B}$ cells are regulated by various cytokines such as a proliferation-inducing ligand (APRIL) and B cell-activating factor (BAFF, also known as B Lymphocyte Stimulator (BLys) or TNF- and APOL-related leukocyte expressed ligand (TALL-1). BAFF, a member of the tumor necrosis factor superfamily (TNFSF13B) and an IFN stimulated gene, is produced by many cell types including monocytes, macrophages, dendritic cells, neutrophils and activated $\mathrm{T}$ cells. ${ }^{6}$ The expression of BAFF is stimulated by interferon-gamma (IFN- $\gamma$ ), interleukin (IL)-10 and CD40 ligand. ${ }^{6}$ Previous studies have shown that circulating BAFF is increased in several autoimmune and chronic inflammatory disorders. ${ }^{7-9}$ Elevated BAFF levels is also found in patients with hepatitis $C$ virus (HCV) infection, particularly in individuals with cryoglobulinemia. ${ }^{10,11}$ IFN-based treatments up-regulated BAFF levels in patients with chronic HCV infection, especially in those achieving viral clearance. ${ }^{11}$ Additionally, a recent study has showed that BAFF concentration was elevated in patients with $\mathrm{CHB}$ in comparison with healthy controls and the level of BAFF was associated with unfavorable clinical consequences including cirrhosis and HCC. ${ }^{12}$ Together, these results suggest that BAFF may contribute to the pathogenesis of chronic viral hepatitis and may potentially predict treatment outcome in patients with $\mathrm{CHB}$.

The aim of this study was to determine the relationship between plasma BAFF levels and treatment response following PEG-IFN in patients with $\mathrm{HBeAg}$-positive $\mathrm{CHB}$. In conjunction with BAFF levels, we also examined plasma concentrations of APRIL and CXCL10, a marker of IFN-stimulated genes (ISG). ${ }^{13}$ Our data clearly demonstrated that measuring both BAFF and CXCL10 at baseline might facilitate individualized decision-making before initiating PEG-IFN therapy.

\section{Methods \\ Patients}

Forty-two patients with $\mathrm{HBeAg}$-positive $\mathrm{CHB}$, who were treated with 48-week PEG-IFN-alfa2a (180 $\mu \mathrm{g} /$ week) between January 2010 and May 2015 and followed up for at least 24 weeks after therapy at the King Chulalongkorn Memorial Hospital, Bangkok, Thailand were enrolled. These patients had available stored plasma samples at baseline and during treatment. All these patients had HBsAg positivity, elevated serum alanine aminotransferase (ALT) and serum HBV DNA levels for at least 6 months before therapy. Patients with HCV and/or human immunodeficiency virus (HIV) co-infection were excluded. Virological response (VR) was defined as $\mathrm{HBeAg}$ seroconversion (HBeAg clearance and generation of anti-HBe) plus HBV DNA level $<2,000 \mathrm{IU} / \mathrm{mL}$ at 24 weeks after complete treatment. Combined response (CR) was defined by VR plus HBsAg decline $\geq 1.0 \log _{10} \mathrm{IU} / \mathrm{mL}$ at 24 weeks post treatment.

The study was approved by the Institutional Review Board of the Faculty of Medicine, Chulalongkorn University, Bangkok, Thailand and participants had provided written informed consent. The study followed the Helsinki Declaration and Good Clinical Practice guidelines.

\section{Serological and virological assays}

Qualitative measurements of HBsAg, HBeAg and Anti-HBe were tested by commercial available enzyme-linked immunosorbent assays (Abbott Laboratories, Chicago, IL). Serum HBsAg quantification was assessed by Elecsys HBsAgII Quant reagent kits (Roche Diagnostics, Indianapolis, IN) and HBV DNA levels were tested by Abbott Real Time HBV assay (Abbott Laboratories). HBV genotyping and mutations in the precore (PC, G1896A) and basal core promoter (BCP; A1762T and/or G1764A)) regions were assessed by direct sequencing, as described previously. ${ }^{14}$ Patients were then classified as being infected with wild type (WT) or mutant HBV.

\section{Enzyme-linked immunosorbent assays}

Plasma BAFF and CXCL10 levels were determined by ELISA (R\&D Systems, Minneapolis, MN) at baseline, during and after therapy (weeks 0, 4, 12, 24, 48 and 72). Plasma APRIL was measured at baseline using Human APRIL Platinum ELISA (eBioscience, Vienna, Austria) according to the manufacturer's protocol.

\section{Statistical analysis}

Statistical analysis was performed with SPSS statistics version 22 (SPSS Inc., Chicago, IL) and GraphPad Prism v5.0 (GraphPad Software, San Diego, CA). Values are presented as mean \pm standard deviation (SD), and percentages as appropriate. Comparisons between groups were assessed by the $\chi^{2}$ or Fisher's exact test for categorical variables and by the MannWhitney $U$-test or Student's $t$-test for quantitative variables. Spearman correlation coefficient was applied to evaluate the correlation between baseline parameters. Areas under the receiver operating characteristic curve (ROC) were used to assess the predictive values of variables for treatment response. Sensitivity, specificity, positive predictive value (PPV), negative predictive value (NPV) and accuracy were calculated in accordance with standard methods. Univariate and multivariate logistic regression were used to assess odd ratios relating pre-treatment variables associated with treatment response. A $p$ value $<0.05$ was considered statistically significant. 


\section{Results}

Baseline patient characteristics

In this cohort, 17 (40.5\%), $11(26.2 \%)$ and 3 (7.1\%) patients achieved VR, CR and HBsAg clearance, respectively. Baseline characteristics of all patients and those with and without CR are shown in Table 1. Patients who achieved CR (responders) had significantly lower baseline BAFF concentrations but had significantly higher baseline CXCL10 levels than non-responders. In addition, responders had lower frequencies of PC and BCP mutations than non-responders. There was no significant difference between groups in the distribution of patient's gender, HBV genotypes, mean HBV DNA, HBsAg and APRIL levels. Baseline characteristics of patients in relation to VR and HBsAg clearance are shown in Supplementary Table 1.
Baseline levels of BAFF, APRIL and CXCL10 in relation to treatment outcome are shown in Figure 1. For BAFF concentrations, patients with VR compared to those without VR had a significant lower mean baseline level (762.4 \pm 199.7 vs. $923.7 \pm 231.1 \mathrm{pg} / \mathrm{mL}, P=0.024)$. Similar findings were observed in relation to patients with and without CR (722.6 \pm 208.6 vs. $906.6 \pm 221.6 \mathrm{pg} / \mathrm{mL}, P=0.021)$ and with and without HBsAg clearance $(556.3 \pm 77.7$ vs. $881.6 \pm 222.2 \mathrm{pg} / \mathrm{mL}$, $P=0.017)$. For APRIL levels, the corresponding figures were as following: VR vs no VR $(2.3 \pm 2.4$ vs. $6.5 \pm 11.7 \mathrm{pg} / \mathrm{mL}, P$ $=0.131)$, CR vs no $\mathrm{CR}(2.5 \pm 2.8$ vs. $5.7 \pm 10.8 \mathrm{pg} / \mathrm{mL}, P=$ $0.368)$ and $\mathrm{HBs} A g$ clearance vs no clearance (1.0 \pm 0.2 vs. 5.1 $\pm 9.6 \mathrm{pg} / \mathrm{mL}, P=0.472$ ). Regarding baseline CXCL10, levels at baseline differed between VR vs non VR $(493.9 \pm 328.0$ vs.

Table 1. Baseline characteristics of patients in relation to combined response

\begin{tabular}{|c|c|c|c|c|}
\hline Characteristics & $\begin{array}{l}\text { All patients } \\
\qquad(\mathrm{n}=42)\end{array}$ & $\begin{array}{l}\text { Responders } \\
\quad(\mathbf{n}=11)\end{array}$ & $\begin{array}{l}\text { Non-responders } \\
\qquad(\mathrm{n}=\mathbf{3 1})\end{array}$ & $P$ value \\
\hline Age, year & $33.8 \pm 8.2$ & $32.7 \pm 8.4$ & $34.2 \pm 8.2$ & 0.609 \\
\hline Male sex, n (\%) & $28(66.7 \%)$ & $7(63.6 \%)$ & $21(67.7 \%)$ & 0.804 \\
\hline ALT, U/I & $97.2 \pm 71.5$ & $93.9 \pm 59.2$ & $98.3 \pm 76.3$ & 0.863 \\
\hline \multicolumn{5}{|l|}{ HBV genotypes, n (\%) } \\
\hline B & $5(11.9 \%)$ & $1(9.1 \%)$ & $4(12.9 \%)$ & 0.737 \\
\hline $\mathrm{C}$ & $37(88.1 \%)$ & $10(90.9 \%)$ & $27(87.1 \%)$ & \\
\hline PC and BCP Mutation, n (\%) & $21(50 \%)$ & $2(18.2 \%)$ & $19(61.3 \%)$ & $0.014^{*}$ \\
\hline $\log _{10} \mathrm{HBV}$ DNA, IU/ml & $7.2 \pm 1.1$ & $7.4 \pm 1.2$ & $7.1 \pm 1.1$ & 0.541 \\
\hline $\log _{10} \mathrm{HBsAg}, \mathrm{IU} / \mathrm{ml}$ & $3.9 \pm 0.7$ & $4.1 \pm 0.8$ & $3.9 \pm 0.7$ & 0.371 \\
\hline BAFF, pg/ml & $858.4 \pm 230.7$ & $722.6 \pm 208.6$ & $906.6 \pm 221.6$ & $0.021^{*}$ \\
\hline APRIL, ng/ml & $4.8 \pm 9.3$ & $2.5 \pm 2.8$ & $5.7 \pm 10.8$ & 0.368 \\
\hline CXCL10, pg/ml & $356.0 \pm 250.7$ & $562.5 \pm 371.6$ & $282.8 \pm 136.7$ & $0.033^{\star}$ \\
\hline
\end{tabular}

Values are presented as means \pm SD unless otherwise specified.

ALT, alanine aminotransferase; PC, Precore; BCP, Basic core promoter; Responders, patients achieved combined response

\section{(A) BAFF}

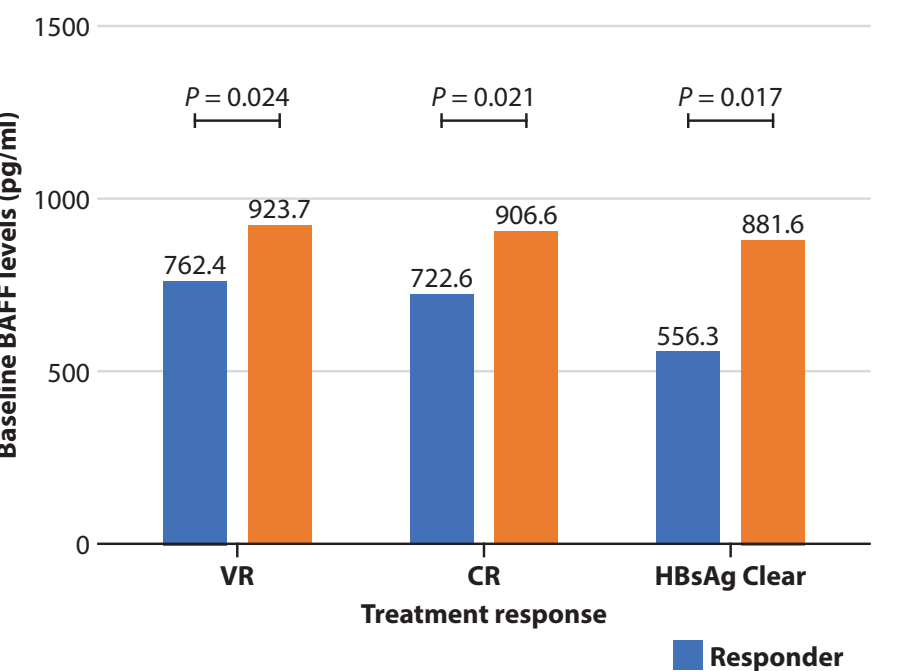

\section{(B) CXCL10}

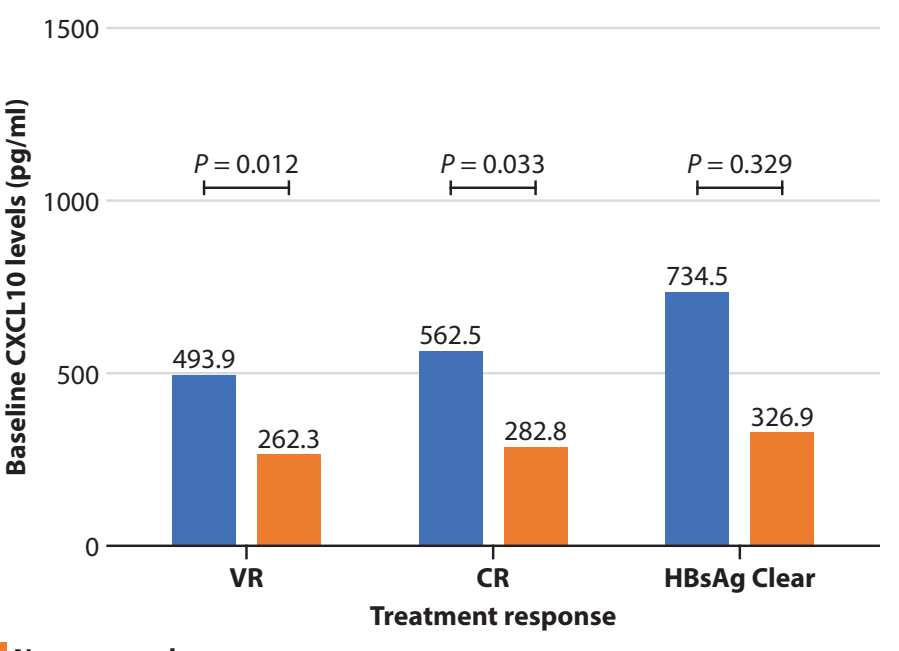

Non-responder

Figure 1. Baseline levels of (A) BAFF (B) CXCL10 in relation to treatment response 
$262.3 \pm 114.1 \mathrm{pg} / \mathrm{mL}, P=0.012)$ and $\mathrm{CR}$ vs non $\mathrm{CR}(562.5$ \pm 371.6 vs. $282.8 \pm 136.7 \mathrm{pg} / \mathrm{mL}, P=0.033$ ). However, there were no significant differences with and without HBsAg clearance $(734.5 \pm 552.5$ vs. $326.9 \pm 198.9 \mathrm{pg} / \mathrm{mL}, P=0.329)$.

Baseline plasma BAFF levels were positively correlated with baseline plasma APRIL levels ( $\mathrm{r}=0.471, P=0.005$ ) but there was no correlation with plasma CXCL10 levels ( $\mathrm{r}$ $=0.04, P=0.801)$, HBV DNA, HBsAg or ALT levels. Baseline CXCL10 levels correlated with ALT levels $(r=0.369, P$ $=0.016$ ), but did not correlated with HBV DNA and HBsAg concentrations.

\section{Plasma BAFF and CXCL10 kinetics in relation to combined response}

Regardless of treatment response, plasma BAFF levels were significantly elevated after the beginning of PEG-IFN therapy and decreased after the end of treatment (Figure 2A). Mean BAFF levels were significantly different between those with and without $\mathrm{CR}$ at week $0(722.6 \pm 208.6$ vs. $906.6 \pm 221.6$ $\mathrm{pg} / \mathrm{mL}, P=0.021)$ and week $72(742.3 \pm 219.8$ vs. $938.3 \pm$ $228.4 \mathrm{pg} / \mathrm{mL}, P=0.018)$. However, there were no significant differences between groups at other time points. In addition, the mean changes from baseline at weeks 4, 12, 24, 48 and 72 were not different between responders and non-responders.

\section{(A) BAFF}
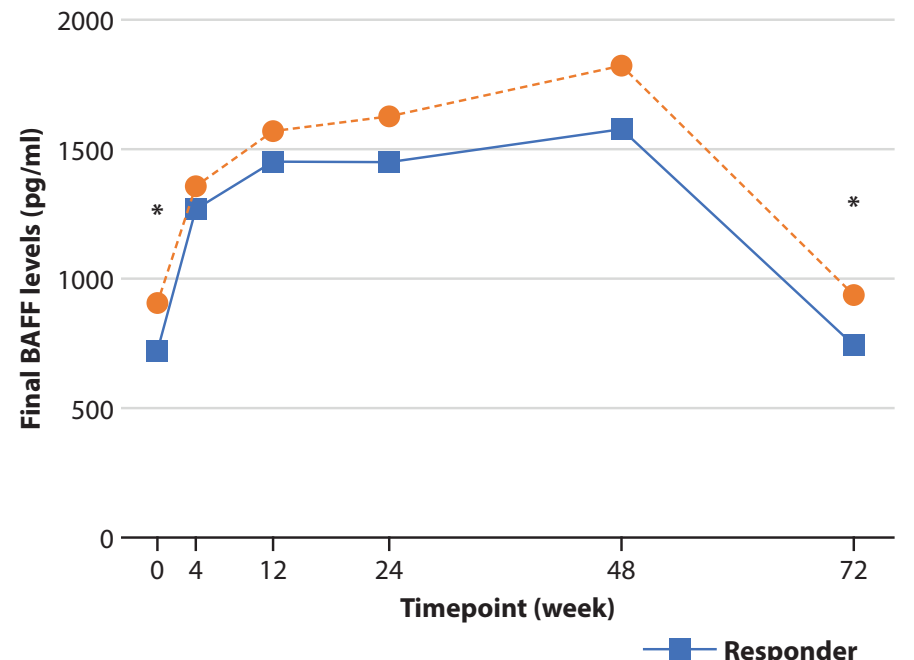

For circulating CXCL10, individuals with a CR compared to no CR had higher levels at baseline (562.5 \pm 371.6 vs. 282.8 $\pm 136.7 \mathrm{pg} / \mathrm{mL}, P=0.033)$ and week $12(603.4 \pm 175.1$ vs. $431.6 \pm 141.3 \mathrm{pg} / \mathrm{mL}, P=0.002)$ but not at week $72(162.5$ \pm 70.7 vs. $235.9 \pm 152.1 \mathrm{pg} / \mathrm{mL}, P=0.133$ ) (Figure $2 B$ ). The results showed no difference between groups at other time points. Considering the dynamic changes from baseline, the mean decline of CXCL10 levels was significantly different between individuals with a CR compared to no CR at week 24 $(202.3 \pm 409.2$ vs. $-89.9 \pm 109.2 \mathrm{pg} / \mathrm{mL}, P=0.042)$, week 48 $(240.7 \pm 377.0$ vs. $-20.2 \pm 156.8 \mathrm{pg} / \mathrm{mL}, P=0.047)$ and week $72(400.0 \pm 399.0$ vs. $46.8 \pm 163.8 \mathrm{pg} / \mathrm{mL}, P=0.015)$.

\section{Cut-off values of baseline BAFF and CXCL10 in predicting combined response}

The cut-off values of BAFF and CXCL10 for predicting CR are shown in Supplementary Figure 1. The area under ROC curves (AUROC) of BAFF and CXCL10 were 0.74 (95\% confidence interval (CI), 0.55-0.93; $P=0.018)$ and 0.77 (95\%CI, $0.60-0.94 ; P=0.008)$, respectively. The optimal cut-off values for BAFF and CXCL10 were 770 and $320 \mathrm{pg} / \mathrm{mL}$, respectively. For baseline circulating APRIL, the AUROC was $0.62(95 \% \mathrm{CI}$, $0.40-0.84 ; P=0.273$ ) and the best cut-off level was $1.30 \mathrm{ng} /$ $\mathrm{mL}$. The sensitivity, specificity, PPV, NPV and accuracy for the prediction of CR of these markers are shown in Table 2.

\section{(B) CXCL10}

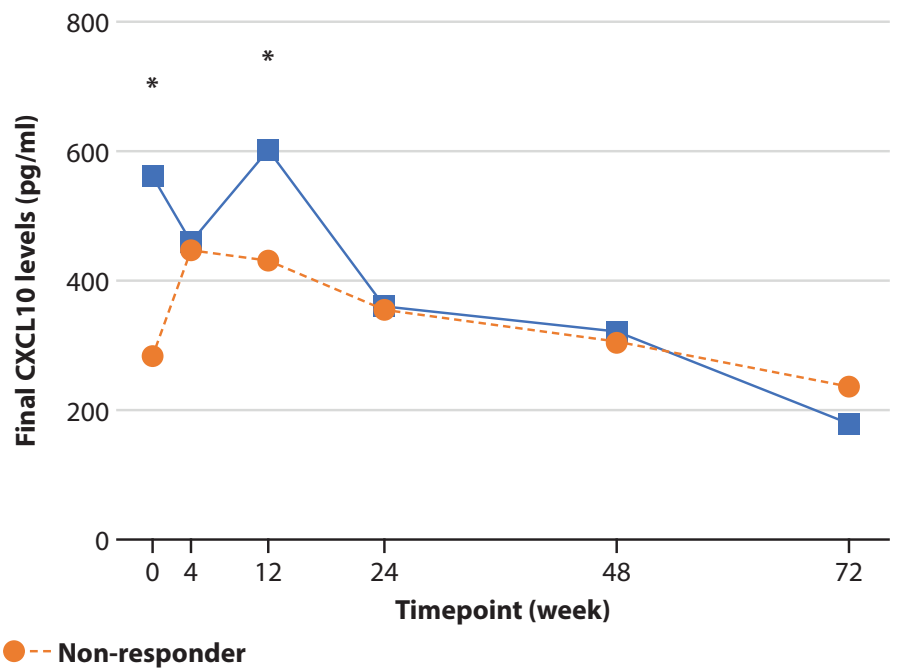

Figure 2. Kinetics of BAFF and CXCL10 levels during PEG-IFN therapy. (A) BAFF (B) CXCL10 ${ }^{\star P}<0.05$

Table 2. Cut-off levels of parameters to predict combined response

\begin{tabular}{lcccccc}
\multicolumn{1}{c}{ Parameters } & Cut-off values & Sensitivity, \% & Specificity, \% & PPV, \% & NPV, \% & Accuracy, \% \\
\hline BAFF & $770 \mathrm{pg} / \mathrm{ml}$ & 72.7 & 71.0 & 47.1 & 88.0 & 71.4 \\
CXCL10 & $320 \mathrm{pg} / \mathrm{ml}$ & 72.7 & 74.2 & 50.0 & 88.5 & 73.8 \\
CXCL10/BAFF ratio & 0.45 & 72.7 & 83.9 & 61.5 & 89.7 & 81.0 \\
\hline
\end{tabular}

NPV, negative predictive value; PPV, positive predictive value 
Table 3. Logistic regression analysis of baseline characteristics to predict combined response

\begin{tabular}{|c|c|c|c|c|c|}
\hline \multirow{3}{*}{ Factors } & \multirow{3}{*}{ Categories } & \multicolumn{4}{|c|}{ Combined response } \\
\hline & & \multicolumn{2}{|c|}{ Univariate analysis } & \multicolumn{2}{|c|}{ Multivariate analysis } \\
\hline & & OR $(95 \% \mathrm{CI})$ & $P$ value & OR $(95 \% \mathrm{CI})$ & $P$ value \\
\hline Age, year & $<40$ vs. $\geq 40$ & $1.1(0.2-5.1)$ & 0.912 & & \\
\hline Sex & Male vs. Female & $0.8(0.2-3.5)$ & 0.804 & & \\
\hline ALT, IU/ml & $<100$ vs. $\geq 100$ & $0.9(0.2-4.3)$ & 0.912 & & \\
\hline HBV genotypes & B vs. C & $0.7(0.1-6.8)$ & 0.739 & & \\
\hline $\mathrm{PC} / \mathrm{BCP}$ mutants & Wild type vs. Mutants & $7.1(1.3-38.8)$ & $0.023^{*}$ & $4.2(0.5-33.8)$ & 0.175 \\
\hline $\log _{10}$ HBV DNA, IU/ml & $<7.0$ vs. $\geq 7.0$ & $4.2(0.8-22.8)$ & 0.094 & & \\
\hline $\log _{10} \mathrm{HBsAg}, \mathrm{IU} / \mathrm{ml}$ & $<4.0$ vs. $\geq 4.0$ & $2.4(0.6-10.0)$ & 0.222 & & \\
\hline APRIL, ng/ml & $<1.3$ vs. $\geq 1.3$ & $2.5(0.6-11.3)$ & 0.235 & & \\
\hline BAFF, $\mathrm{pg} / \mathrm{ml}$ & $<770$ vs. $\geq 770$ & $7.7(1.6-36.2)$ & $0.010^{*}$ & $16.1(1.5-174.9)$ & $0.022^{*}$ \\
\hline CXCL10, pg/ml & $\geq 320$ vs. $<320$ & $12.9(2.3-73.0)$ & $0.004^{*}$ & $24.2(2.1-280.6)$ & $0.011^{*}$ \\
\hline
\end{tabular}

ALT, alanine aminotransferase; PC, Precore; BCP, Basic core promoter; OR, odd ratio; CI, confident interval

As the expression of circulating BAFF and CXCL10 exhibited an opposite pattern, we further analyzed the ratio of CXCL10 to BAFF levels. The AUROC of CXCL10/BAFF ratio was 0.86 (95\%CI, 0.73-0.99; $P<0.001$. Based on ROC analysis, the best cut-off point of CXCL10/BAFF ratio was 0.45 . At this optimal value, the sensitivity, specificity, PPV, NPV and accuracy for predicting CR were 72.7, 83.9, 61.5, 89.7 and 81.0 , respectively (Table 2 ).

\section{HBsAg kinetics in relation to baseline CXCL10/BAFF ratio}

To compare HBsAg kinetics in relation to baseline CXCL10/BAFF ratio, the best cut-off value of 0.45 was applied. Patients with a high ratio $(\geq 0.45 ; \mathrm{n}=14)$ compared with those with low ratio $(<0.45 ; \mathrm{n}=28)$ had similar levels of HBsAg ( $4.0 \pm 0.7$ vs. $\left.3.9 \pm 0.7 \log _{10} \mathrm{IU} / \mathrm{mL}, P=0.561\right)$ but a trend towards a greater HBsAg decline from baseline: week 4 $\left(0.3 \pm 0.5\right.$ vs. $\left.0.1 \pm 0.3 \log _{10} \mathrm{IU} / \mathrm{mL}, P=0.060\right)$, week $12(0.6 \pm$ 0.7 vs. $\left.0.2 \pm 0.3 \log _{10} \mathrm{IU} / \mathrm{mL}, P=0.097\right)$, week 24 (1.2 \pm 1.3 vs. $\left.0.5 \pm 0.6 \log _{10} \mathrm{IU} / \mathrm{mL}, P=0.088\right)$, week 48 (1.6 \pm 1.6 vs. $0.7 \pm$ $\left.0.9 \log _{10} \mathrm{IU} / \mathrm{mL}, P=0.086\right)$ and week $72(1.6 \pm 1.8$ vs. $0.5 \pm 1.1$ $\log _{10} \mathrm{IU} / \mathrm{mL}, P=0.045$ ) (Supplementary Figure 2).

\section{Predictors of combined response at baseline}

Univariate and multivariate analyses were performed in order to identify pre-treatment predictors of CR. Selected baseline factors included sex, age, ALT, HBV genotype, viral mutations, HBV DNA, HBsAg, plasma BAFF, APRIL and CXCL10 levels. In univariate analysis, parameters associated with $\mathrm{CR}$ were the presence of WT virus (no PC and/or BCP mutants), low plasma BAFF $(<770 \mathrm{pg} / \mathrm{ml})$ and high CXCL10 $(\geq 320 \mathrm{pg} / \mathrm{ml}$ ) levels. In multivariate analysis, only low BAFF and high CXCL10 levels were independent predictors for CR (Table 3).

\section{Discussion}

The ultimate but difficult to achieve end-point in the management of patients with $\mathrm{HBeAg}$-positive $\mathrm{CHB}$ is $\mathrm{HBsAg}$ clearance/seroconversion, which is considered to be a functional cure resulting in favorable long-term clinical outcomes including reduced rates of cirrhosis and HCC development. ${ }^{15}$ HBsAg clearance was observed in approximately $7 \%$ of our report, a rate comparable to previous data in patients with HBeAg-positive CHB treated with PEG-IFN (3-7\%). ${ }^{1}$ Given the low rate of achieving HBsAg clearance after PEG-IFN therapy, a well-recognized and more realistic goal in clinical practice is $\mathrm{HBeAg}$ seroconversion with sustained virological suppression (VR). In the natural history of $\mathrm{CHB}$, however, HBV DNA levels fluctuate more often than HBsAg levels. Thus, low HBV DNA level at a single time point might not guarantee persistently viral suppression. Another valuable parameter reflecting effective immunity following antiviral therapy is a reduction in serum HBsAg concentrations. Indeed, significant HBsAg decline represents an immune control of chronic HBV infection, helps differentiate patients likely to achieve sustained off-treatment response and offers a good prediction of subsequent HBsAg clearance in long-term follow-up. ${ }^{16}$ Based on this concept, we used a combined response of VR plus a significant decline of HBsAg level as the main therapeutic outcome in this cohort.

In the present study, we aimed at investigating whether baseline and on therapy kinetics of plasma CXCL10 and BAFF levels were associated with treatment response to PEGIFN in Thai patients with HBeAg-positive CHB. Our data clearly demonstrated that high circulating CXCL10 level prior to treatment was positively correlated with increased likelihood of achieving CR. In contrast, an increased baseline BAFF level was negatively correlated with treatment outcome. 
Considering the reciprocal relationship between CXCL10 and BAFF levels, the calculation of baseline CXCL10/BAFF ratio could increase the sensitivity for predicting a treatment response. Based on the best cut-off value, the ratio of 0.45 displayed a PPV and NPV of approximately $62 \%$ and $90 \%$, respectively. These results indicate that CXCL10/BAFF ratio may be applicable to individualize decision-making before initiation of PEG-IFN therapy in patients with HBeAg-positive CHB.

The novel finding in this study was the strong association of low plasma BAFF levels at the start of PEG-IFN with a successful treatment response. Lower baseline BAFF levels were associated with a rapid decline in HBsAg levels and higher rates of HBsAg clearance at the end of follow-up. Interestingly, similar findings in patients with chronic HCV infection also demonstrated that responders to IFN-based therapy had lower pre-treatment BAFF levels than non-responders. ${ }^{10}$ Moreover, BAFF levels were significantly higher in patients with acute $\mathrm{HCV}$ infection evolving to chronicity than in those with a self-limited course. ${ }^{17}$ In patients with $\mathrm{CHB}$, a stepwise elevated BAFF concentrations were correlated with disease severity included cirrhosis and HCC. ${ }^{12}$

Of note, our data showed that baseline plasma BAFF concentrations did not correlate with circulating CXCL10 levels. However, plasma BAFF levels gradually increased during PEG-IFN therapy and decreased to levels similar to baseline after cessation of the treatment. These findings indicated that the up-regulation of BAFF was mainly regulated by the effect of PEG-IFN, similar to previous reports in patients with chronic HCV infection undergoing IFN-based therapy. ${ }^{10,11,17}$ In contrast to pre-treatment levels, the kinetics of BAFF was not correlated with treatment outcome as responders and non-responders had comparable pattern and dynamic changes in BAFF concentrations during PEG-IFN therapy. As a consequence, monitoring on-treatment BAFF might not provide additional information in predicting PEG-IFN responsiveness in our cohort.

The mechanisms by which baseline BAFF concentrations modulate therapeutic outcome of PEG-IFN in patients with $\mathrm{HBeAg}$-positive $\mathrm{CHB}$ are largely unknown. BAFF has emerged as a cytokine that plays an essential role in B cell proliferation, differentiation, survival and antibody production. ${ }^{6}$ By secreting neutralizing antibodies, B cells are able to minimize viral spread and contribute to viral elimination. In addition, $\mathrm{B}$ cells are capable of acting as antigen-presenting cells and modulating $\mathrm{T}$ cell responses. During HBV infection, the process of $\mathrm{B}$-cell activation and its interaction with $\mathrm{HBV}$-specific $\mathrm{T}$ cells is considered to be crucial for diverse clinical outcomes of infected individuals. ${ }^{4}$ It has been shown that vigorous $\mathrm{T}$ cell responses induce $\mathrm{B}$ cell activation, which in turn leads to anti-viral $\mathrm{T}$ cell responsiveness and favors neutralizing antibody formation. In contrast, the interaction of $\mathrm{B}$ cells and $\mathrm{T}$ cells could also up-regulate the expression of PD-1, a hallmark of $\mathrm{T}$ cell exhaustion during chronic viral infection. ${ }^{18}$ Recent data have shown that total B-cell hyper-activation but impaired generation of $\mathrm{HBV}$-specific B-cells are commonly found in chronic $\mathrm{HBV}$ infection and reversal of these processes is associated with HBsAg seroconversion. ${ }^{19}$ Moreover, it has been demonstrated in a cell culture model that $\mathrm{HBeAg}$ itself is able to regulate monocyte function and promote BAFF activation. ${ }^{20}$ Given these observations, we propose that high BAFF concentrations found in this study might reflect $\mathrm{B}$-cell hyper-activation, thereby altering $\mathrm{T}$ cell function and reducing response to PEG-IFN in patients with $\mathrm{HBeAg}$-positive CHB. A better understanding of the mechanism by which BAFF and B cells modulate T-cell function in the presence and absence of PEG-IFN in patients with $\mathrm{CHB}$ requires further investigations.

CXCL10 is a pro-inflammatory chemokine that plays an essential role in the pathogenesis of chronic viral hepatitis. Upon its binding to the chemokine receptor 3 (CXCR3), CXCL10 activates T lymphocytes and natural killer (NK) cells undergo chemotaxis. ${ }^{13}$ In $\mathrm{HBV}$ infection, increased intrahepatic expression of CXCL10 leads to accumulation of inflammatory cells, which results in the activation of immune-mediated liver injury. ${ }^{21,22}$ It has been shown in an animal model of transgenic mice that inhibition of CXCL10 significantly reduces the recruitment of inflammatory cells and severity of liver damage. ${ }^{23}$ Elevated circulating CXCL10, which is correlated with high intrahepatic CXCL10 expression, has also been shown to be correlated with the degree of liver inflammation and fibrosis in HBV-infected individuals. ${ }^{24}$ In patients with $\mathrm{CHB}$, high baseline circulating CXCL10 levels have a predictive value of response to PEG-IFN or NA therapy. ${ }^{25-30}$ In addition, CXCL10 is an ISG and therefore would be expected to increase following PEG-IFN. In line with these reports, our data confirmed that higher CXCL10 levels were associated with favorable outcome of PEG-IFN therapy. Given positive correlation of baseline CXCL10 levels with therapeutic outcome, increased circulating CXCL10 concentrations might represent a pre-existing active immunity attributable to higher response rates in patients with $\mathrm{CHB}$.

Interestingly, we also found that dynamic decline of CXCL10 was associated with an increased likelihood of treatment response during PEG-IFN therapy. Specifically, decreasing CXCL10 levels from baseline was significantly higher in patients achieving CR. However, such finding was not detected among non-responders. Indeed, a similar trend was also observed in previous studies demonstrating that down-relation of circulating CXCL10 is more pronounced among responders than non-responders treated with PEG-IFN or NA. ${ }^{26,30}$ As CXCL10 expression in $\mathrm{HBV}$ infection primarily contributes to liver injury, ${ }^{31}$ significant decline in responders during and after treatment could reflect an improved immune control of HBV infection after successful antiviral therapy.

Although this is the first demonstration of the role of BAFF in predicting a treatment response in $\mathrm{CHB}$, there were several limitations. First, the sample size was relatively small. Second, the study was retrospective but this might not lead to any confounding of the results because BAFF levels were significantly increase during therapy and then decreased to baseline after PEG-IFN cessation. Moreover, the present study included only patients with $\mathrm{HBeAg}$ - positive $\mathrm{CHB}$ but did not recruit patients with $\mathrm{HBeAg}$-negative $\mathrm{CHB}$. 


\section{Conclusion}

In summary, our results strongly showed that baseline CXCL10 and BAFF levels were predictive of a clinically relevant response to PEG-IFN in Thai patients with HBeAg-positive CHB. Thus, combined measurement of these biomarkers of immune activity prior to PEG-IFN not only would motivate patients to adhere to treatment but also could maximize therapeutic cost-effectiveness. As the sample size of patients enrolled in this study was limited, a replicate study with larger number of patients is needed to verify these observations and would provide further insights into the role of BAFF and $\mathrm{B}$ cell response in patients with $\mathrm{CHB}$.

\section{Acknowledgements}

This study was funded by the Grant for Chula Research Scholar [CU-GRS-60-06-30-03], the 100 ${ }^{\text {th }}$ Anniversary Chulalongkorn University Fund for Doctoral Scholarship, the $90^{\text {th }}$ Anniversary Chulalongkorn University Fund (Ratchadaphiseksomphot Endowment Fund), National Research University (NRU59-026-HR), the annual government budget in the year 2016-2017, and The Thailand Research Fund (TRF) Senior Research Scholar. The study was also supported by Center of Excellence in Hepatitis and Liver Cancer, Chulalongkorn University. SRL is funded by the National Health and Medical Researchc Council (NHMRC) of Australia with a practitioner fellowship.

\section{Conflict of interest}

The authors who have taken part in this study declare that they do not have anything to disclose regarding conflict of interest with respect to the manuscript.

\section{References}

1. Trepo C, Chan HL, Lok A. Hepatitis B virus infection. Lancet. 2014;384 (9959):2053-63.

2. Konerman MA, Lok AS. Interferon Treatment for Hepatitis B. Clin Liver Dis. 2016;20(4):645-65.

3. Bertoletti A, Ferrari C. Innate and adaptive immune responses in chronic hepatitis B virus infections: towards restoration of immune control of viral infection. Gut. 2012;61(12):1754-64.

4. Bertoletti A, Ferrari C. Adaptive immunity in HBV infection. J Hepatol. 2016;64(1 Suppl):S71-83.

5. Lu L. Frontiers in B-cell immunology. Cell Mol Immunol. 2013;10(2):95-6.

6. Lied GA, Berstad A. Functional and clinical aspects of the B-cell-activating factor (BAFF): a narrative review. Scand J Immunol. 2011;73(1):1-7.

7. Cheema GS, Roschke V, Hilbert DM, Stohl W. Elevated serum B lymphocyte stimulator levels in patients with systemic immune-based rheumatic diseases. Arthritis Rheum. 2001;44(6):1313-9.

8. Salazar-Camarena DC, Ortiz-Lazareno PC, Cruz A, Oregon-Romero E, Machado-Contreras JR, Munoz-Valle JF, et al. Association of BAFF, APRIL serum levels, BAFF-R, TACI and BCMA expression on peripheral B-cell subsets with clinical manifestations in systemic lupus erythematosus. Lupus. 2016;25(6):582-92.

9. Stohl W, Cheema GS, Briggs WS, Xu D, Sosnovtseva S, Roschke V, et al. B lymphocyte stimulator protein-associated increase in circulating autoantibody levels may require CD4+ T cells: lessons from HIV-infected patients. Clin Immunol. 2002;104(2):115-22.

10. Lake-Bakaar G, Jacobson I, Talal A. B cell activating factor (BAFF) in the natural history of chronic hepatitis $\mathrm{C}$ virus liver disease and mixed cryoglobulinaemia. J Clin Exp Immunol. 2012;170(2):231-7.

11. Sene D, Limal N, Ghillani-Dalbin P, Saadoun D, Piette JC, Cacoub P. Hepatitis C virus-associated B-cell proliferation--the role of serum B lymphocyte stimulator (BLyS/BAFF). Rheumatology. 2007;46(1):65-9.
12. Yang C, Li N, Wang Y, Zhang P, Zhu Q, Li F, et al. Serum levels of B-cell activating factor in chronic hepatitis B virus infection: association with clinical diseases. J Interferon Cytokine Res. 2014;34(10):787-94.

13. Cornberg M, Wiegand SB. ImPortance of IP-10 in hepatitis B. Antivir Ther. 2016;21(2):93-6.

14. Tangkijvanich P, Sa-Nguanmoo P, Mahachai V, Theamboonlers A, Poovorawan Y. A case-control study on sequence variations in the enhancer II/core promoter/precore and X genes of hepatitis B virus in patients with hepatocellular carcinoma. Hepatol Int. 2010;4(3):577-84.

15. Zeisel MB, Lucifora J, Mason WS, Sureau C, Beck J, Levrero M, et al. Towards an HBV cure: state-of-the-art and unresolved questions--report of the ANRS workshop on HBV cure. Gut. 2015;64(8):1314-26.

16. Cornberg M, Wong VW, Locarnini S, Brunetto M, Janssen HL, Chan HL. The role of quantitative hepatitis B surface antigen revisited. J Hepatol. 2017;66(2):398-411.

17. Tarantino G, Marco VD, Petta S, Almasio PL, Barbaria F, Licata A, et al. Serum BLyS/BAFF predicts the outcome of acute hepatitis C virus infection. J Viral Hepat. 2009;16(6):397-405.

18. Herkel J, Carambia A. Let it B in viral hepatitis? J Hepatol. 2011;55(1):5-7.

19. Xu X, Shang Q, Chen X, Nie W, Zou Z, Huang A, et al. Reversal of B-cell hyperactivation and functional impairment is associated with $\mathrm{HBsAg}$ seroconversion in chronic hepatitis B patients. Cell Mol Immunol. 2015;12 (3):309-16

20. Lu B, Zhang B, Wang L, Ma C, Liu X, Zhao Y, et al. Hepatitis B Virus e Antigen Regulates Monocyte Function and Promotes B Lymphocyte Activation. Viral Immunol. 2017;30(1):35-44.

21. Zhou Y, Wang S, Ma JW, Lei Z, Zhu HF, Lei P, et al. Hepatitis B virus protein $\mathrm{X}$-induced expression of the CXC chemokine IP-10 is mediated through activation of NF-kappaB and increases migration of leukocytes. J Biol Chem. 2010;285(16):12159-68.

22. Narumi S, Tominaga Y, Tamaru M, Shimai S, Okumura H, Nishioji K, et al. Expression of IFN-inducible protein-10 in chronic hepatitis. J Immunol. 1997;158(11):5536-44.

23. Kakimi K, Lane TE, Wieland S, Asensio VC, Campbell IL, Chisari FV, et al. Blocking chemokine responsive to gamma-2/interferon (IFN)-gamma inducible protein and monokine induced by IFN-gamma activity in vivo reduces the pathogenetic but not the antiviral potential of hepatitis $B$ virus-specific cytotoxic T lymphocytes. J Exp Med. 2001;194(12):1755-66.

24. Wang Y, Yu W, Shen C, Wang W, Zhang L, Liu F, et al. Predictive Value of Serum IFN-gamma inducible Protein-10 and IFN-gamma/IL-4 Ratio for Liver Fibrosis Progression in CHB Patients. Sci Rep. 2017;7:40404.

25. Sonneveld MJ, Arends P, Boonstra A, Hansen BE, Janssen HL. Serum levels of interferon-gamma-inducible protein 10 and response to peginterferon therapy in HBeAg-positive chronic hepatitis B. J Hepatol. 2013;58(5): 898-903.

26. Wang Y, Zhao C, Zhang L, Yu W, Shen C, Wang W, et al. Predictive value of interferon-gamma inducible protein $10 \mathrm{kD}$ for hepatitis $\mathrm{B}$ e antigen clearance and hepatitis B surface antigen decline during pegylated interferon alpha therapy in chronic hepatitis B patients. Antiviral Res. 2014; 103:51-9.

27. Jaroszewicz J, Ho H, Markova A, Deterding K, Wursthorn K, Schulz S, et al. Hepatitis B surface antigen (HBsAg) decrease and serum interferon -inducible protein-10 levels as predictive markers for HBsAg loss during treatment with nucleoside/nucleotide analogues. Antivir Ther. 2011;16(6): 915-24.

28. Papatheodoridis G, Goulis J, Manolakopoulos S, Margariti A, Exarchos X, Kokkonis G, et al. Changes of HBsAg and interferon-inducible protein 10 serum levels in naive $\mathrm{HBeAg-negative} \mathrm{chronic} \mathrm{hepatitis} \mathrm{B} \mathrm{patients} \mathrm{under}$ 4-year entecavir therapy. J Hepatol. 2014;60(1):62-8.

29. Willemse SB, Jansen L, de Niet A, Sinnige MJ, Takkenberg RB, Verheij J, et al. Intrahepatic IP-10 mRNA and plasma IP-10 levels as response marker for $\mathrm{HBeAg}$-positive chronic hepatitis B patients treated with peginterferon and adefovir. Antiviral Res. 2016;131:148-55.

30. Hou FQ, Wu XJ, Wang Y, Chen J, Liu YZ, Ren YY, et al. Rapid downregulation of programmed death-1 and interferon-gamma-inducible protein-10 expression is associated with favourable outcome during antiviral treatment of chronic hepatitis B. J Viral Hepat. 2013;20 Suppl 1: 18-26.

31. Wang J, Zhao JH, Wang PP, Xiang GJ. Expression of CXC chemokine IP-10 in patients with chronic hepatitis B. Hepatobiliary Pancreat Dis Int. 2008;7(1):45-50. 